\title{
Autologous Stem Cell Transplantation in Elderly Patients is Safe and is not associated with a Higher Frequency of Readmission Compared to Younger Patients. A Single Center Experience
}

Farina $\mathbf{M}^{*}$, Crippa C, Cerqui E, Daffini R, Soverini G, Dalceggio D, Pelizzari AM, Cattaneo C, Belotti A, Ribolla $R$ and Rossi $G$

Department of Hematology, Spedali Civili Brescia, Italy

*Corresponding author: Mirko Farina, Department of Hematology, Spedali Civili Brescia, Italy

Received: October 03, 2018; Accepted: November 01, 2018; Published: November 08, 2018

\section{Background}

High dose chemotherapy and Autologous Stem Cell Transplantation (ASCT) is an effective treatment strategy for many adult Patients (pts) with Non-Hodgkin Lymphoma (NHL) and Multiple Myeloma (MM) and it is increasingly performed also in selected patients older than 65 years.

\section{Aims}

Data on toxicity and complications rate of ASCT in elderly patients are scarce. Herein we evaluated complications and rehospitalization rate within 3 months in patients older than $65 \mathrm{yrs}$ undergoing ASCT.

\section{Methods}

We retrospectively analyzed 231 consecutive patients who underwent ASCT at our Institution between January 2016 and December 2017, focusing on the group of pts aged $>65$ yrs. Their characteristics, clinical course and outcome were analysed and compared with younger pts.

\section{Results}

Seventy-two of 231 (31\%) ASCT pts were > 65 yrs. Diagnosis was MM in $52(72 \%)$ and NHL in 20 pts (28\%) respectively. Median age was 69 (range 65-76). Patients' comorbidities or significant laboratory abnormalities are summarized in (Table 1). Based on clinical judgement, conditioning regimen dose intensity was reduced in 10 pts (14\%). In $12 \%(6 / 52)$ of MM pts melphalan dose was reduced to $140 \mathrm{mg} / \mathrm{m}^{2}$ (4) or $100 \mathrm{mg} / \mathrm{m}^{2}$ (2). FEAM dose was reduced at $75 \%$ in 4 NHL pts (20\%) [1,2]. Pts achieved hematology recovery after a median of 10 days (6-13) and were discharged after 13 days (929). Infectious complications were the most frequent adverse event during the aplastic phase [3-5].

Fever of Unknown Origin (FUO) developed in 31 pts (43\%), sepsis in $16(22 \%)$ and pneumonia in 10 (14\%). Among noninfectious complications, WHO grade $>$ III mucositis occurred in 12
Table 1:

\begin{tabular}{|l|c|c|}
\hline & $\mathrm{n}(72)$ & $\%$ \\
\hline Hypertension & 26 & 36 \\
\hline Diabetes mellitus & 9 & 12.5 \\
\hline Previous thrombotic events (TIA, AMI, PE) & 5 & 7 \\
\hline Thyroids dysfunction & 4 & 5 \\
\hline Sleep apnea syndrome & 3 & 4 \\
\hline Lupus anticoagulant & 2 & 2.7 \\
\hline Chronic renal failure & 2 & 2.7 \\
\hline Cardiac arrhythmia & 5 & 7 \\
\hline Neurological disease & 3 & 4.1 \\
\hline
\end{tabular}

TIA: Transient Ischemic Attack; AMI: Acute Myocardial Infarction; PE: Pulmonary Embolism

Table 2:

\begin{tabular}{|c|c|c|c|}
\hline & $\begin{array}{l}\text { Not re admitted } \\
\text { n } 56(78 \%)\end{array}$ & $\begin{array}{c}\text { Re-admitted } \\
\text { n } 16(72 \%)\end{array}$ & $\mathrm{p}$-value \\
\hline Median age (years) & $69(66-75)$ & $67(65-75)$ & \\
\hline \multicolumn{4}{|l|}{ Disease } \\
\hline MM & $41(73 \%)$ & $10(62.5 \%)$ & 0.53 \\
\hline LNH & $15(27 \%)$ & $6(37.5 \%)$ & \\
\hline \multicolumn{4}{|l|}{ Comorbidity } \\
\hline$<2$ & $30(53.5 \%)$ & $8(50 \%)$ & \\
\hline$>=2$ & $16(28.5 \%)$ & $3(19 \%)$ & 0.46 \\
\hline$>=3$ & $10(17.8 \%)$ & $5(31 \%)$ & \\
\hline \multicolumn{4}{|l|}{ Aplasia adverse events } \\
\hline FUO & $21(37.5 \%)$ & $10(62.5 \%)$ & 0.09 \\
\hline Mucositis \{grade III WHO\} & $12(21 \%)$ & $7(43.7 \%)$ & 0.1 \\
\hline Sepsis & $13(23 \%)$ & $3(18.7 \%)$ & 0.9 \\
\hline Pneumonia & $7(12.5)$ & $3(18.7 \%)$ & 0.68 \\
\hline Neutropenic enteritis & $1(1.7 \%)$ & $3(18.7 \%)$ & 0.03 \\
\hline FA/TPSV & $3(5 \%)$ & $2(12.5 \%)$ & 0.3 \\
\hline $\begin{array}{l}\text { Time to neutrophills recovery } \\
(\mathrm{N}>500) \text { (days; range) }\end{array}$ & $10(6-13)$ & $10(9-13)$ & \\
\hline $\begin{array}{l}\text { Time to discharge from ASCT } \\
\text { (days; range) }\end{array}$ & $13(9-29)$ & $13(10-24)$ & \\
\hline
\end{tabular}

pts $(17 \%)$, neutropenic enteritis in $4(5.5 \%)$ and cardiac arrhythmia (atrial fibrillation or TPSV) in 3 (4\%).

Readmission to the Hematology Unit within 3 months from ASCT occurred after a median of 32 days (14-120 [s2] days) in 16 of 72 pts (22\%) [6]. Most of the re-admissions were due to FUO (37.5\%) or infections (sepsis in 12.5\%, pneumonia in 19\%, diarrhea in $12.5 \%$, Human Respiratory Syncytial Virus infection in 6\%). Other causes included: hyporexia/vomiting, respiratory distress, disease relapse, acute cholecystitis, appendicitis and unrelated neoplasia. Table 2 compares the characteristics of elderly pts needing readmission or not after ASCT. The risk of being re-admitted did not vary according
Ann Hematol Oncol - Volume 5 Issue 8 - 2018 ISSN : 2375-7965 | www.austinpublishing group.com Farina et al. ( ) All rights are reserved
Citation: Farina M, Crippa C, Cerqui E, Daffini R, Soverini G, Dalceggio D, et al. Autologous Stem Cell Transplantation in Elderly Patients is Safe and is not associated with a Higher Frequency of Readmission Compared to Younger Patients. A Single Center Experience. Ann Hematol Oncol. 2018; 5(8): 1222. 
to age, type of disease, time to neutrophil recovery, time to discharge or number of comorbidities at ASCT, whereas the development of neutropenic enteritis ( $\mathrm{p} 0.05$; HR 3.84, 0.98-15.06) or WHO grade III mucositis (p 0.04; HR 2.79, 1.06-7.37) during ASCT were significantly associated with subsequent re-admission.

The re-hospitalization rate after ASCT of pts aged $<65$ was $18 \%$ (29/159), not significantly different from elderly pts. Moreover, no differences were found in time to re-admission (median 30 vs. 32 days), and in the causes of re-hospitalization [FUO/sepsis ( $45 \%$ vs. $50 \%)$, diarrhea (17 vs. $12.5 \%)$, pneumonia (10\% vs. $19 \%)$, disease progression $(21 \% v s .6 \%$, p: 0.39$)$ ] in younger $v s$. elderly pts, respectively. No transplant-related death was observed in pts over 65 yrs, while 1 younger pts died of within 3 months from ASCT.

\section{Conclusion}

ASCT performed in pts older than 65 yrs shows a low rate of short-term complications without unexpected adverse events. The rate of post-ASCT readmission is similar to younger pts and its risk is higher in pts developing severe mucositis or neutropenic enteritis during ASCT.

\section{References}

1. Stamatoullas. Autologous stem cell transplantation for patients aged 60 years or older with refractory or relapsed classical Hodgkins Lymphoma: a retrospective analysis from the French Society of Bone Marrow Transplantation and Cell Therapies (SFGM-TC); / Bone Marrow Transplantation. 2016; 51: 928-932.

2. Hermet. Autologous Hematopoietic stem cell transplantation in elderly patients (> 70 years) with non- Hodgkins Lymphoma: A French Society of Bone Marrow Transplantation and Cellular Therapy retrospective study. J Geriatr Oncol. 2015; 6: 346-352.

3. Iantunen $\mathrm{E}$. Autologous stem cell transplantation on elderly patients ( $>$ or $=60$ years) with diffuse large B- cell Lymphoma: an analysis based on data in the European Blood and Bone Marrow Transplantation registry. Haematologica. 2008; 93: 1837-1842.

4. Gohil SH. Autologous stem cell transplantation outcomes in elderly patients with B cell Non-Hodgkin Lymphoma. Br J Haematol. 2015; 17: 197-204.

5. Sharma M. Older patients with myeloma derive similar benefit from autologous transplantation. Biol Blood Marrow Transplant. 2014; 20: 1796-1803.

6. Sirohi B. The role of autologous transplantation in patients with multiple myeloma aged 65 years and over. Bone Marrow Transplant. 2000; 25: 533539.
Ann Hematol Oncol - Volume 5 Issue 8 - 2018

ISSN : 2375-7965 | www.austinpublishinggroup.com

Farina et al. (C) All rights are reserved
Citation: Farina M, Crippa C, Cerqui E, Daffini R, Soverini G, Dalceggio D, et al. Autologous Stem Cell Transplantation in Elderly Patients is Safe and is not associated with a Higher Frequency of Readmission Compared to Younger Patients. A Single Center Experience. Ann Hematol Oncol. 2018; 5(8): 1222. 